\title{
USE OF TRANSOBTURATOR SUBURETHRAL TAPE FOR SURGICAL TREATMENT OF STRESS URINARY INCONTINENCE IN A RENAL TRANSPLANT PATIENT
}

Alexandre Danilovic, Fabio Baracat, Nelson Íleo Dias Montellatto, William Carlos Nahas, and Antonio Marmo Lucon

Female stress urinary incontinence (SUI) is being treated successfully with placement of tension-free vaginal tape. ${ }^{1}$ The use of synthetic mesh in renal transplant patients is rarely reported. No case of surgical treatment of SUI in a renal transplant patient using transobturator suburethral tape is listed on MEDLINE. The transobturator tape technique is a minimally invasive procedure that avoids the retropubic space by inserting a tension-free synthetic mesh underneath the middle of the urethra between the obturator foramens. ${ }^{2}$

\section{DESCRIPTION OF THE CASE}

A 56-year-old female presented with stress urinary incontinence for 2 months. She complained about episodes of urinary leaks during coughing or physical exercise requiring the use of 1 to 3 pads per day with a severe impact on her quality of life. No dysuria, urgency, nocturia, or sensation of postvoid residual urine was reported. She had 3 vaginal deliveries, an appendectomy 40 years previously, and a renal transplantation in left iliac fossa 6 years previously to treat end-stage renal disease due to hypertension. At presentation, she was taking the following medications: mycophenolate mofetil $1500 \mathrm{mg} / \mathrm{d}$, cyclosporin $150 \mathrm{mg} / \mathrm{d}$, prednisone $7.5 \mathrm{mg} / \mathrm{d}$, atenolol 100 $\mathrm{mg} / \mathrm{d}$, captopril $50 \mathrm{mg} / \mathrm{d}$, and simvastatin $10 \mathrm{mg} / \mathrm{d}$. The physical examination revealed a renal graft in left iliac fossa, trophic vaginal mucosa, and no pelvic organ prolapse. Urethral hypermobility was demonstrated with a positive Crystle test ${ }^{3}$, and urine loss was $40 \mathrm{~g} / 24$-hour

Division of Urology, Hospital das Clínicas, Faculty of Medicine, University of São Paulo - São Paulo/SP, Brazil.

Email: alexandre.danilovic@sbu.org.br measured using a pad weighing test. The urine culture was negative, and plasma creatinine was $0.9 \mathrm{mg} / \mathrm{dL}$. Urodynamic evaluation showed a bladder capacity of 480 $\mathrm{mL}$, normal compliance and sensation, absence of detrusor overactivity, Valsalva leak point pressure of $80 \mathrm{~cm}$ $\mathrm{H} 2 \mathrm{O}$, maximal flow rate of $9.3 \mathrm{~mL} / \mathrm{s}$, and detrusor pressure at maximal flow of $12.3 \mathrm{~cm} \mathrm{H} 2 \mathrm{O}$.

A tension-free polypropylene tape was inserted under regional anesthesia, and antibiotic prophylaxis with cefazolin at induction was used. The tape was inserted in a horizontal plane underneath the middle of the urethra between the obturator foramens via an inside-out technique ${ }^{4}$ (Figure 1) and was followed by cystoscopy to confirm absence of bladder injury. The procedure was uneventful and lasted 25 minutes, with an estimated blood loss of $20 \mathrm{~mL}$. The patient was discharged the next day after spontaneous micturition. At a 30-day follow-up, no stress urinary incontinence, pads uses, or voiding difficulty was reported.

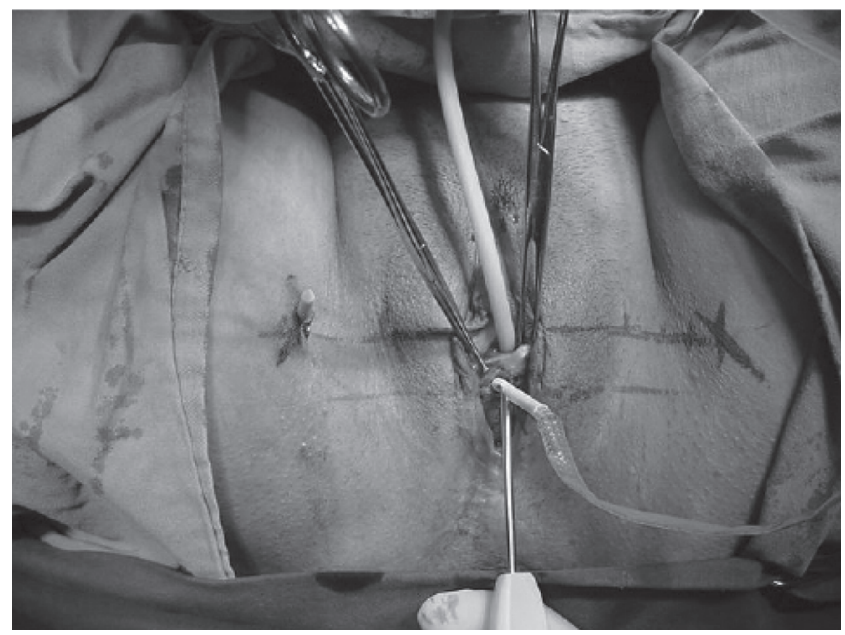

Figure 1 - Transobturator needle insertion: inside-out technique 


\section{DISCUSSION}

The transobturator suburethral tape is a novel technique that is being applied for surgical treatment of SUI., There are no listed MEDLINE reports on this technique for a transplant patient. This approach prevents the risk of bladder, bowel, or vascular injuries because it avoids the retropubic space. Although we performed an endoscopic evaluation, there is no need for cystoscopy, which reduces operative time. ${ }^{2,5}$ Renal transplant patients particularly ben- efit from these advantages because the procedure avoids the theoretical risk of graft injury. No urinary or surgical site infection occurred in this case, despite the use of synthetic mesh in this immunosuppressed patient. Previous data on the use of synthetic material in transplant patients revealed low rates of infection. ${ }^{6}$ The inside-out transobturator technique for insertion of a suburethral tape is a good option for the treatment of SUI in renal transplant patients because of its minimally invasive character and low rates of complications.

\section{REFERENCES}

1. Abouassaly R, Steinberg JR, Lemieux M, Marois C, Gilchrist LI, Bourque JL, et al. Complications of tension-free vaginal tape surgery: a multi-institutional review. BJU Int. 2004; 94: 110

2. Delorme E, Droupy S, deTayrac R, Delmas V. Transobturator tape (Uratape): a new minimally-invasive procedure to treat female urinary incontinence. Eur Urol. 2004; 45: 203.

3. Crystle CD, Charme LS, Copeland WE. Q-tip test in stress urinary incontinence. Obstet Gynecol. 1971;38(2):313-5.

4. deLeval J. Novel surgical technique for the treatment of female stress urinary incontinence: transobturator vaginal tape inside-out. Eur Urol. 2003; 44(6):724-30
5. deTayrac R, Deffieux X, Droupy S, Chaveaud-Lambling A, CalvaneseBenamour L, Fernandez H. A prospective randomized trial comparing tension-free vaginal tape and transobturator suburethral tape for surgical treatment of stress urinary incontinence. Am J Obstet Gynecol. 2004; 190: 602 .

6. Mazzucchi E, Nahas WC, Antonopoulos I, Ianhez LE, Arap S. Incisional hernia and its repair with polypropylene mesh in renal transplant recipients. J Urol. 2001; 166: 816. 